\title{
Velleratretraol, an unusual highly functionalized lactarane sesquiterpene from Lactarius vellereus
}

\author{
Du-Qiang Luo ${ }^{1}$, Li-Yan Zhao ${ }^{1}$, Yao-Long Shi ${ }^{1}$, Hong-Liang Tang ${ }^{1}$, Yu-Ye $\mathrm{Li}^{2}$, Liu-Meng Yang ${ }^{2}$, \\ Yong-Tang Zheng ${ }^{2}$, Hua-Jie $\mathrm{Zhu}^{3}$ and Ji-Kai Liu $^{3}$
}

An unusual highly functionalized lactarane sesquiterpene, named velleratretraol (1), was isolated from the ethanol extract of the fruiting body of the mushroom Lactarius vellereus. Its structure was determined through spectroscopic analysis and singlecrystal X-ray diffraction studies. The proposed assignment of the absolute configuration is based on computational results. It showed weak activity against HIV-1 cells with an effective concentration of $68.0 \mu \mathrm{g} \mathrm{ml}^{-1}$ and a selectivity index of 2.0. The Journal of Antibiotics (2009) 62, 129-132; doi:10.1038/ja.2008.25; published online 23 January 2009

Keywords: lactarane sesquiterpene; Lactarius vellereus; velleratretraol; X-ray

\section{INTRODUCTION}

The Russulaceae family is one of the largest in the subdivision Basidiomycotina in Whittaker's Kingdom of Fungi and comprises hundreds of species. ${ }^{1}$ Sesquiterpenes play an important biological role in a majority of the Lactarius species. They are responsible for the pungent and bitter taste of the milky juice, the color change in the latex upon air exposure, ${ }^{2}$ and they constitute a chemical defense system against intruders such as bacteria, fungi, animals and insects. ${ }^{3}$ The fungal subdivision Basidiomycotina produces many toxic sesquiterpenes derived from the protoilludane skeleton. This skeleton is transformed and rearranged into a multitude of compounds. Fungal sesquiterpenes formed via the humulane-protoilludane biosynthetic pathway are characteristic for the subdivision Basidiomycotina. The largest group of sesquiterpenes, belonging to the classes of lactaranes, secolactaranes, marasmanes, isolactaranes, norlactaranes and caryophyllanes, are believed to be biosynthesized from humulane. ${ }^{4}$ Fungi of the genus Lactarius have been shown to be a good source of bioactive secondary metabolites. ${ }^{5-7}$ China is extraordinarily rich in higher fungi, with over 6000 species reported to belong to about 1200 genera. In our on-going research to explore the biologically active natural products of the higher fungi of China, ${ }^{8-12}$ the chemical constituents of the fruiting bodies of Lactarius vellereus were investigated. This report describes the isolation and structure elucidation of an unusual highly functionalized lactarane sesquiterpene, named velleratretraol (1), and its anti-HIV activity.

\section{RESULTS AND DISCUSSION}

Velleratretraol (1) was isolated as colorless crystals. The molecular formula of 1 was determined to be $\mathrm{C}_{15} \mathrm{H}_{24} \mathrm{O}_{6}$ on the basis of high-resolution electrospray ionization mass spectrometry (HR-ESIMS) $\left(\left[\mathrm{M}+\mathrm{NH}_{4}\right]^{+}\right.$at $\mathrm{m} / z 318.1911$ in combination with ${ }^{1} \mathrm{H}$ - and ${ }^{13} \mathrm{C}-\mathrm{NMR}$ data (Table 1)). The IR data suggested the presence of a hydroxy $\left(3463,3408\right.$ and $\left.3355 \mathrm{~cm}^{-1}\right)$ moiety. The ${ }^{13} \mathrm{C}-\mathrm{NMR}$ spectrum of 1 showed 15 resonances, which could be further classified into three Me groups $\left(\delta, 29.5,31.6\right.$ and 31.8), three $\mathrm{CH}_{2}(\delta, 40.4,43.5$ and 44.2), three oxymethines $(\delta, 71.2,99.3$ and 112.9), two aliphatic methines $(\delta, 42.7$ and 52.3), three oxygenated quaternary carbon atoms $(\delta, 82.0$, 85.0 and 88.4$)$ and one quaternary carbon atom $(\delta, 35.9)$ by analysis of the DEPT spectra. An analysis of the ${ }^{1} \mathrm{H}-\mathrm{NMR}$ spectrum indicated the presence of three methyl groups at $\delta=1.03(\mathrm{~s}), 1.12$ (s) and 1.27 (s). The first two resonances were ascribed to geminal methyl groups, and the third one was ascribed to the methyl group on the carbon atom bearing the tetramethylene oxide carbocycle group. In particular, a doublet occurring at $\delta=3.73(\mathrm{~d}, 11.8)$ was attributed to the C-4 bearing a secondary $\mathrm{OH}$ group, and two resonances at $\delta=5.55$ (s) and 5.35 (s) were assigned at C-14 and C-15, respectively. Its formula indicated a sesquiterpene skeleton containing 4 degrees of unsaturation. The structure was suggested to be a tetracyclic sesquiterpene.

The key connectivity of the protons and carbon atoms was further established by the ${ }^{1} \mathrm{H}$ - and ${ }^{13} \mathrm{C}-\mathrm{NMR}$, hetero multiple quantum correlation spectra, ${ }^{1} \mathrm{H}-{ }^{1} \mathrm{H}$ COSY and hetero multiple band correlation (HMBC) spectra. The cross-peaks between $\mathrm{H}-2$ and $\mathrm{H}-3 / \mathrm{H}-9$, $\mathrm{H}-3$ and $\mathrm{H}-2 / \mathrm{H}-4 / \mathrm{H}-11, \mathrm{H}-9$ and $\mathrm{H}-2$, and $\mathrm{H}-11$ and $\mathrm{H}-3$ were observed in the ${ }^{1} \mathrm{H}-{ }^{1} \mathrm{H}$ COSY spectrum. The further connectivity of the above partial structures was deduced from the HMBC spectrum (Figure 1). The HMBC correlations from the acetal methine proton $(\mathrm{H}-15)$ to the one oxygenated quaternary carbon at $\delta_{\mathrm{c}} 88.4(\mathrm{C}-1)$ and

${ }^{1}$ College of Life Science, Key Laboratory of Pharmaceutical Chemistry and Molecular Diagnosis, Ministry of Education and Research Center of Biotechnology of Hebei Province, Hebei University, Baoding, China; ${ }^{2}$ Kunming Institute of Zoology, Chinese Academy of Sciences, Kunming, China and ${ }^{3}$ State Key Laboratory of Phytochemistry and Plant Resources in West China, Kunming Institute of Botany, Chinese Academy of Sciences, Kunming, China

Correspondence: Dr D-Q Luo, College of Life Science, Key Laboratory of Pharmaceutical Chemistry and Molecular Diagnosis, Ministry of Education and Research Center of Biotechnology of Hebei Province, Hebei University, Baoding 71002, China; Y-T Zheng, Kunming Institute of Zoology, Chinese Academy of Sciences, Kunming, China; $\mathrm{H}-\mathrm{J}$ Zhu, State Key Laboratory of Phytochemistry and Plant Resources in West China, Kunming Institute of Botany, Chinese Academy of Sciences, Kunming, China. E-mail: duqiangluo@163.com

Received 13 September 2008; accepted 17 December 2008; published online 23 January 2009 
Table 1 NMR spectral data for velleratretraol (1) in $\mathrm{CD}_{3} \mathrm{OD}$

\begin{tabular}{|c|c|c|c|c|}
\hline & ${ }^{13} \mathrm{C}$ & ${ }^{1} H$ & $\begin{array}{l}{ }^{1} H_{-}{ }^{1} H \\
\mathrm{COSY}\end{array}$ & $H M B C$ \\
\hline 1 & $88.4(\mathrm{~s})$ & & & \\
\hline 2 & $52.3(d)$ & $2.23(\mathrm{~m})$ & $\mathrm{H}-3, \mathrm{H}-9$ & $C-4,11$ \\
\hline 3 & 42.7 (d) & $2.18(\mathrm{~m})$ & $\mathrm{H}-2,4,11$ & $C-2,4$ \\
\hline 4 & 71.2 (d) & $3.73(d, 11.8)$ & $\mathrm{H}-2,3$ & $C-3,6,14$ \\
\hline 5 & $85.0(\mathrm{~s})$ & & & \\
\hline 6 & $82.0(\mathrm{~s})$ & & & \\
\hline 7 & $40.4(\mathrm{t})$ & $\begin{array}{l}2.43(\mathrm{~d}, 13.5) \\
1.73(\mathrm{~d}, 13.5)\end{array}$ & & $\mathrm{C}-1,2,5,6,8,15$ \\
\hline 8 & 29.5 (q) & $1.27(\mathrm{~s})$ & & $C-1,2,7$ \\
\hline 9 & $44.2(q)$ & $\begin{array}{l}1.37(d, 13.1) \\
1.45(d d, 6.7 \\
12.6)\end{array}$ & $\mathrm{H}-2$ & $\mathrm{C}-2,10,12,13$ \\
\hline 10 & $35.9(\mathrm{~s})$ & & & \\
\hline 11 & $43.5(t)$ & $\begin{array}{l}1.53(\mathrm{~d}, 9.2, \\
13.9) \\
1.46(\mathrm{~m})\end{array}$ & $\mathrm{H}-3$ & $\mathrm{C}-3,4,10,12,13$ \\
\hline 12 & 31.6 (q) & 1.03 (s) & & $C-9,10,11,13$ \\
\hline 13 & $31.8(q)$ & 1.12 (s) & & C-9, 10, 11, 12 \\
\hline 14 & 99.3 (d) & $5.35(\mathrm{~s})$ & & $\mathrm{C}-4,5,15$ \\
\hline 15 & $112.9(\mathrm{~d})$ & $5.55(\mathrm{~s})$ & & $\mathrm{C}-1,14$ \\
\hline
\end{tabular}

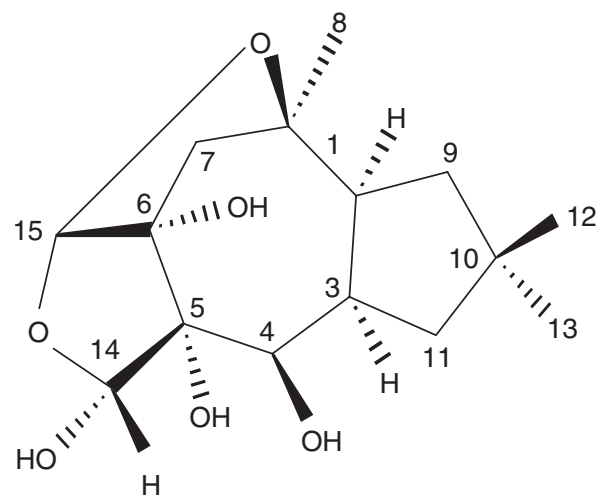

Figure 1 Key $1 \mathrm{H}-1 \mathrm{H} \operatorname{COSY}(-)$ and $\operatorname{HMBC}(\rightarrow)$ correlations of 1 .

the oxymethine carbon at $\delta_{\mathrm{c}} 99.3(\mathrm{C}-14)$, from the oxymethine proton $\left(\delta_{\mathrm{H}} 5.35, \mathrm{H}-14\right)$ to the acetal carbon at $\delta_{\mathrm{c}} 112.9(\mathrm{C}-15), 71.2(\mathrm{C}-4)$ and $85.0(\mathrm{C}-5)$, as well as from the methylene protons $\left(\delta_{\mathrm{H}} 2.43(\mathrm{~d}, 13.4)\right.$, 1.73 (d, 13.5), H-7) to C-1, C-2, C-5, C-6, C-8 and C-15, indicated the connectivity of $\mathrm{C}-15$ via two individual oxygen bridges to both $\mathrm{C}-14$ and $\mathrm{C}-1$. The HMBC correlations from $\mathrm{H}-12$ to $\mathrm{C}-13, \mathrm{H}-2$ to $\mathrm{C}-11$ and $\mathrm{H}-9$ to $\mathrm{C}-3$ revealed the presence of dimethylcyclopentane. The HMBC spectrum further gave the correlation from Me- $8\left(\delta_{\mathrm{H}}\right.$, $1.27 \mathrm{~s}$ ) to $\mathrm{C}-1, \mathrm{C}-2$ and $\mathrm{C}-7$ indicated the methyl group (C-8) was attached at $\mathrm{C}-1$. Further, the above HMBC correlations also implied that four hydroxyl groups were attached to C-4, C-5, C-6 and C-14. By combining all these data, we were able to assign the planar structure 1 to an unusually oxygenated lactarane skeleton (Figure 2), velleratretraol. The structural assignments were further confirmed by an X-ray structure (Figure 3), which established the relative stereochemistry of $\mathbf{1}$.

For the assignment of absolute configuration, the optical rotation value of compound 1 was computed as $-22.7^{\circ}$ for $(1 R, 2 S, 3 R, 4 R$,

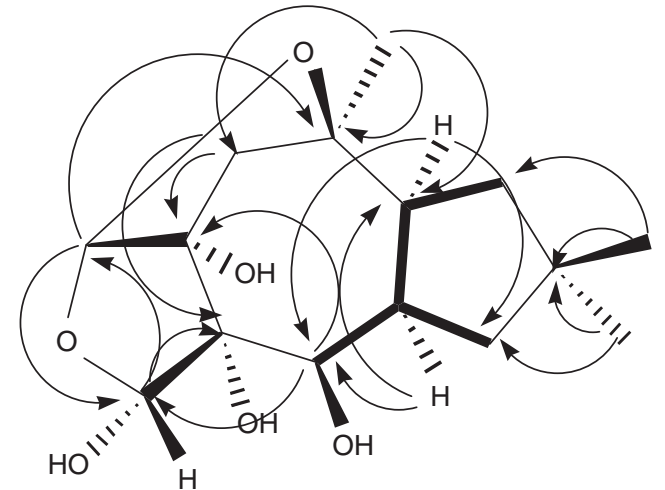

Figure 2 The structure of velleratretraol (1).

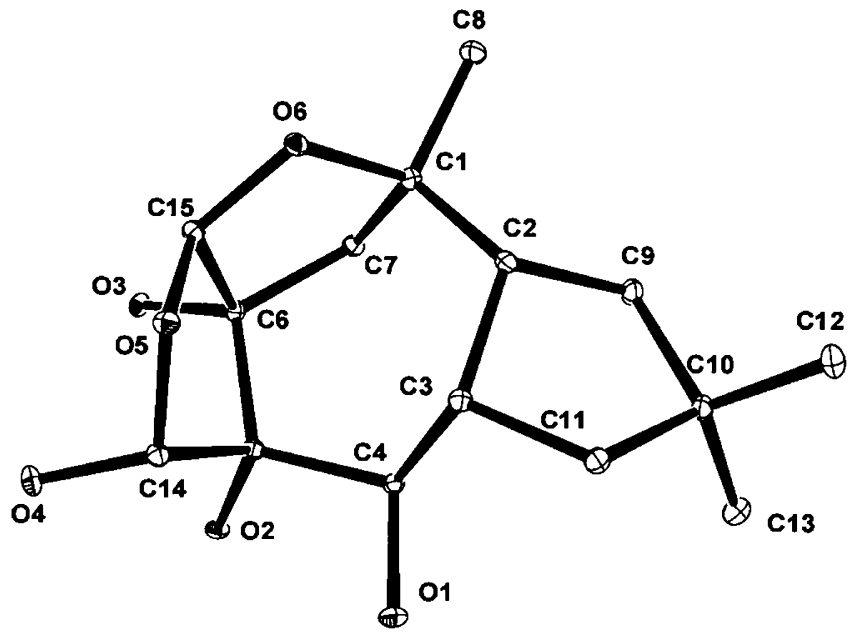

Figure 3 X-ray crystal structure of 1 .

$5 S, 6 R, 14 R$ and $15 R)-1$ using the B3LYP/aug-cc-VDZ//B3LYP/ $6-311+\mathrm{G}(\mathrm{d}, \mathrm{p})$ method. ${ }^{13-15}$ This value is very close to the observed value of $-17.5^{\circ}$, which strongly suggests that the eight stereogenic centers in 1 were $1 R, 2 S, 3 R, 4 R, 5 S, 6 R, 14 R$ and $15 R$.

Compound 1 has a previously unknown carbon skeleton: we propose the name 'verlleratretraol' for this new skeleton. From a biogenetic point of view, the precursor of 1 may be 8-epiisolactarorufin or Lactarorufin A, which has been isolated from the Lactarius genus. ${ }^{16,17} \mathrm{Up}$ to now, none of the known sesquiterpenes has such a skeleton. Therefore, we propose the possible biosynthetic pathway for $\mathbf{1}$ as shown in Scheme 1, in which hydrolysis, oxidation, reduction and condensation reactions are potentially responsible for the above transformations.

Compound 1 also showed cytotoxicity against C8166 cells (inhibitory concentration of $136.5 \mu \mathrm{g} \mathrm{ml}^{-1}$ ) and weak anti-HIV-1 cells activity with an effective concentration of $68.0 \mu \mathrm{g} \mathrm{ml}^{-1}$ and a selectivity index of 2.0 .

\section{EXPERIMENTAL SECTION}

\section{General experimental procedures}

Optical rotations were measured on a Horiba SEPA-300 polarimeter (Horiba, Tokyo, Japan). UV spectra were recorded on a Shimadzu UV-2401PC spectrophotometer (Shimadzu, Kyoto, Japan). IR spectra were obtained with a Tensor 

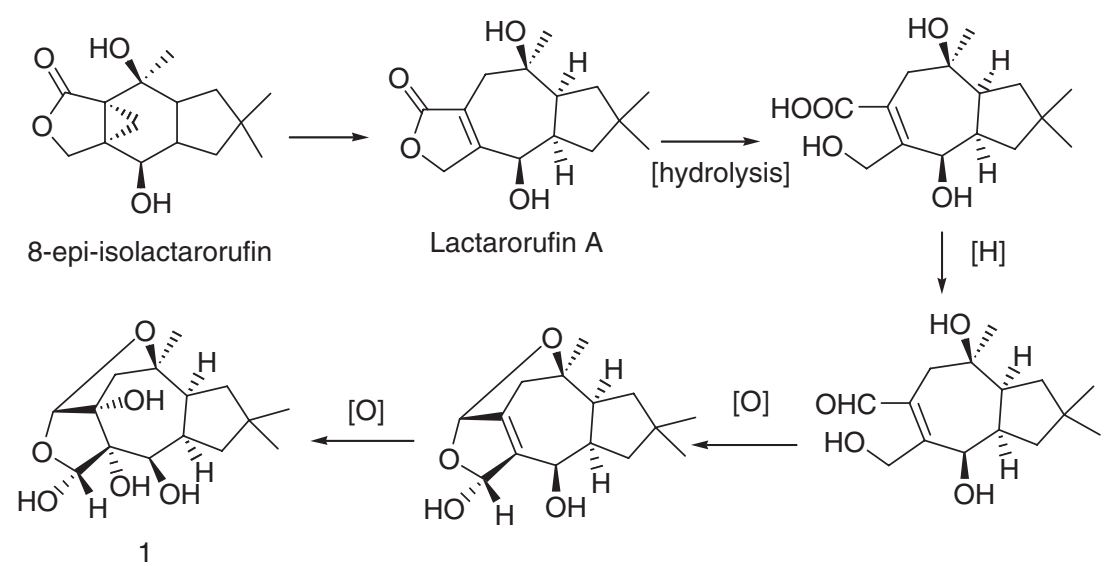

Scheme 1 Biosynthetic pathway proposed for velleratretraol (1) synthesis.

27 (Bruker, Karlsruhe, Germany) using $\mathrm{KBr}$ pellets. NMR spectra were recorded on Bruker AM-400 and Bruker DRX-500 spectrometers (Bruker) in $\mathrm{CD}_{3} \mathrm{OD}$ with TMS as an internal standard. Electrospray ionization and HR-ESI-MS were recorded with an API QSTAR Pulsar I Hybrid LC/MS/MS system (Applied Biosystems, Foster City, CA, USA). Silica gel (200-300 mesh, Qingdao Marine Chemical Inc., Qingdao, PR China) and Sephadex LH-20 (Amersham Biosciences, Uppsala, Sweden) were used for column chromatography. Fractions were monitored by TLC (Qingdao Marine Chemical Inc.). TLC experiments were developed with petroleum ether-EtOAc or $\mathrm{CHCl}_{3}-\mathrm{MeOH}$ solvent systems, and spots were visualized by heating silica gel plates sprayed with $10 \%$ sulfuric acid in $\mathrm{EtOH}$.

\section{Fungal material}

The fresh fruiting bodies of $L$. vellereus were collected at the Ailao mountain, Yunnan Province, China in August 2006, and identified by the staff at the Kunming Institute of Botany, Chinese Academy of Science. A voucher specimen was deposited in the Herbarium of the Kunming Institute of Botany, Chinese Academy of Science.

\section{Extraction and isolation}

The fresh fruiting bodies of L. vellereus $(8.0 \mathrm{~kg})$ were extracted with $95 \%$ aq. $\mathrm{EtOH}(30$ 1). The EtOH soln was evaporated in vacuo to give an extract $(500 \mathrm{~g})$, which was suspended in water and extracted with EtOAc (51). The EtOAc extracts were evaporated under reduced pressure, giving $220 \mathrm{~g}$ of a residue, which was subjected to silica gel column chromatography using mixtures of $\mathrm{CHCl}_{3}$ and $\mathrm{MeOH}$ (from 100:0 to 50:50; each $500 \mathrm{ml}$ ) as the eluents. The fraction eluted by mixtures of $\mathrm{CHCl}_{3}$ and $\mathrm{MeOH}(90: 10 ; 500 \mathrm{ml})$ was first evaporated, then redissolved and, finally, further subjected to silica gel column chromatography, eluting with mixtures of EtOAc and $\mathrm{MeOH}(100: 0,90: 10$, $80: 20,50: 50$; each $200 \mathrm{ml}$ ) to give $1,2,3$ and 4 fractions. Fraction 2 eluted with mixtures of EtOAc and $\mathrm{MeOH}(90: 10 ; 200 \mathrm{ml})$ was evaporated, redissolved with $\mathrm{MeOH}$ and further purified by Sephadex LH-20 chromatography $(\mathrm{MeOH})$ to afford $\mathbf{1}(25 \mathrm{mg})$ as colorless crystal.

Velleratretraol (1): colorless crystals, m.p. $190-192{ }^{\circ} \mathrm{C}(\mathrm{MeOH}) \cdot[\alpha]_{\mathrm{D}}^{20}-17.5$ (c 0.30, MeOH). UV $\lambda_{\max }(\log \varepsilon)(\mathrm{MeOH}): 243(2.54), 204(2.76) \mathrm{nm}$. IR (KBr): 3481, 2988, 2959, 2925, 2881, 1638, 1445, 1388, 1297, 1273, 1045, 968 and $900 \mathrm{~cm}^{-1}$. ${ }^{1} \mathrm{H}$ - and ${ }^{13} \mathrm{C}-\mathrm{NMR}\left(\mathrm{CD}_{3} \mathrm{OD}\right)$ : see Table 1. HR-ESI-MS (pos.): $318.1911\left(\mathrm{C}_{15} \mathrm{H}_{24} \mathrm{O}_{6} \mathrm{NH}_{4}\right)$ (0.20 mmu error).

Crystal data for 1 . Crystals of 1 , crystallized from $\mathrm{MeOH}$, belong to the orthorhombic space group P2(1)2(1)2(1). Crystal data: $\mathrm{C}_{15} \mathrm{H}_{24} \mathrm{O}_{6}, M=300.34$, $a=5.6443$ (18) $\AA, b=8.7693$ (12) $\AA, c=28.892$ (4) $\AA, V=1430.1$ (3) A3, $Z=4$, $d=1.395 \mathrm{mg} \mathrm{m}^{-3}$, Mo K $\alpha$ radiations, linear absorption coefficient $0.107 \mathrm{~mm}^{-1}$. A crystal of dimensions $0.22 \times 0.03 \times 0.02 \mathrm{~mm}^{3}$ was used for X-ray measurements on a Bruker SMART-1000 diffractometer with a graphite monochromator. The total number of independent reflections measured was 18085,2015 of which were considered to be observed $(\mathrm{F} 2>3<\mathrm{F} 2)$. The structure was solved by the direct method SHELXS-97 and expanded using difference Fourier techniques, refined by the program and method NOMCSDP ${ }^{18}$ and full-matrix least-squares calculations. Hydrogen atoms were fixed at calculated positions. The final indices were $R_{\mathrm{f}}=0.0359$ and $R_{\mathrm{w}}=0.0844$. Crystallographic data for the structure of 1 have been deposited in the Cambridge Crystallographic Data Centre (deposition number: CCDC 683072). Copies of these data can be obtained, free of charge, on application to the CCDC through www.ccdc.cam. ac.uk/conts/retriving.html (or from the Cambridge Crystallographic Data Centre, 12, Union Road, Cambridge CB2 1EZ, UK; fax (internat.): +44-1223/ 336-033; E-mail: deposit@ccdc.cam.ac.uk).

\section{Reagents and cell culture}

AZT (3'-azido-3'-deoxythymidine) and MTT (3-(4,5-dimethylthiazol-2-yl)2,5-diphenyltetrazolium bromide) were purchased from Sigma-Aldrich (St Louis, MO, USA). Cells were donated by the Medical Research Council (AIDS Reagent Project, UK), and grown in RPMI-1640 medium supplemented with $10 \%$ heat-inactivated fetal calf serum (Gibro BRL, Gaithersburg, MD, USA), 2 mM L-glutamine, $10 \mathrm{~mm}$ HEPES (4-(2-hydroxyethyl) piperazine-1-ethanesulfonic acid), $50 \mu \mathrm{M}$ 2-mercaptoethanol, $100000 \mathrm{IU} \mathrm{ml}^{-1}$ penicillin and $100 \mu \mathrm{g} \mathrm{ml}^{-1}$ streptomycin sulfate. All cells and virus were stored and resuscitated by common methods. ${ }^{19}$

\section{Cytotoxicity of compound 1 on C8166 cells}

C8166 was one of the host cells for HIV-1. On a microtiter plate, $100 \mu \mathrm{l}$ of $4 \times 10^{5} \mathrm{ml}^{-1}$ cells were seeded. Then $100 \mu \mathrm{l}$ of various concentrations of 1 was added and the cells were incubated at $37^{\circ} \mathrm{C}$ in a humidified atmosphere of $5 \%$ $\mathrm{CO}_{2}$ for $72 \mathrm{~h}$. The cellular toxicity was assessed by an MTT colorimetric assay, the plates were read with a Bio-Tek Elx 800 ELISA reader at 595/630 nm and the $50 \%$ inhibitory concentration was calculated.

\section{Cytopathic-effect inhibition assay of 1}

In the presence of $100 \mu \mathrm{l}$ of various concentrations of $1, \quad$ C8166 cells $\left(4 \times 10^{5} \mathrm{ml}^{-1}\right)$ were infected with HIV-1IIIB at a multiplicity of infection of 0.06 . The final volume was $200 \mu$. The plates were incubated in a humidified incubator at $37^{\circ} \mathrm{C}$ and $5 \% \mathrm{CO}_{2}$. AZT (Sigma) was used as drug control. After 3 days of culture, the cytopathic effect was measured by counting the number of syncytia (multinucleated giant cells) in each well under an inverted microscope and the $50 \%$ effective concentration was calculated.

\section{ACKNOWLEDGEMENTS}

We are grateful to the National Natural Science Foundation of China (30671385), Support Program for Hundred Excellent Innovation Talents from the Universities and The Key Discipline of Bio-Engineering of Hebei University. We also thank Mrs Honggen Wang (The State Key Laboratory of Elemento- 
organic Chemistry, Nankai University, P R China) for assistance in obtaining the X-ray structure.

1 Whittaker, R. H. New concepts of kingdoms of organisms. Science 163, 150-160 (1969).

2 De Bernardi, M., Garlaschelli, L., Toma, L., Vidari, G. \& Vita-Finzi, P. The chemical basis of hot-tasting and yellowing of the mushrooms Lactarius chrysorrheus and L. scrobiculatus. Tetrahedron 49, 1489-1504 (1993).

3 Sterner, O., Bergmann, R., Kihlberg, J. \& Wickberg, B. The sesquiterpenes of Lactarius vellereus and their role in a proposed chemical defense system. J. Nat. Prod. 48, 279-288 (1985).

4 Ayer, W. A. \& Browne, L. M. Terpenoid metabolites of mushrooms and related basidiomycetes. Tetrahedron 37, 2199-2248 (1981).

5 Garlaschelli, L., Mellerio, G., Vidari, G. \& Vita-Finiz, P. New fatty acid esters of drimane sesquiterpenes from Lactarius uvidus. J. Nat. Prod. 57, 905-910 (1994).

6 Kopczacki, P. et al. Synthesis and antifeedant properties of $\mathrm{N}$-benzoylphenylisoserinates of Lactarius sesquiterpenoid alcohols. Phytochemistry 58, 775-787 (2001).

7 Daniewski, W. M. et al. 3, 8-ethers of lactarane sesquiterpenes. Phytochemistry 32, 1499-1502 (1993).

8 Luo, D. Q., Wang, F., Bian, X. Y. \& Liu, J. K. Rufuslactone, a new antifungal sesquiterpene from the fruiting bodies of the Basidiomycete Lactarius rufus. J. Antibiot. 5, 456-459 (2005).
9 Luo, D. Q., Gao, Y., Yang, X. L., Tang, J. G. \& Liu, J. K. Highly oxidized humulane sesquiterpenes from the Basidiomycete Lactarius mitissimus. J. Antibiot. 60, 162-165 (2007).

10 Shao, H. J. et al. A new cytotoxic lanostane triterpenoid from the Basidiomycete Hebeloma versipelle. J. Antibiot. 58, 828-831 (2005).

11 Luo, D. Q. et al. Humulane-type sesquiterpenoids from the Mushroom Lactarius mitissimus. J. Nat. Prod. 69, 1354-1357 (2006).

12 Wang, F., Luo, D. Q. \& Liu, J. K. Aurovertin E, a new polyene pyrone from the Basidiomycete Albatrellus confluens. J. Antibiot. 56, 412-415 (2005).

13 Liu, D. Z. et al. Vibralactone: a lipase inhibitor with an unusual fused betalactone produced by cultures of the basidiomycete Boreostereum vibrans. Org. Lett. 8, 5749-5752 (2006).

14 Crawford, T. D., Owens, L. S., Mary, C. T., Schreiner, P. R. \& Koch, H. Ab initio calculation of optical rotation in (P)-(+)-[4] triangulane. J. Am. Chem. Soc. 127, 1368-1369 (2005).

15 Frisch, M. J. et al. Gaussian 03 User's Reference, Gaussian Inc.: Carnegie, PA, (2003).

16 Daniewski, W. M., Gumulka, M. \& Przesmycka, D. Sesquiterpenes of Lactarius origin, antifeedant structure-activity relationships. Phytochemistry 38, 1161-1168 (1995).

17 Daniewski, W. M., Kocór, M. \& Thorén, S. Isolactarorufin, a novel tetracyclic sesquiterpene lactone from Lactarius rufus. Heterocycles 5, 77-84 (1976).

18 Liu, Y. \& Wu, B. M. A microcomputer analytic system for crystal structure used in chemical laboratories. Chin. Chem. Lett. 3, 637-640 (1992).

19 Wang, Q., Ding, Z. H., Liu, J. K. \& Zheng, Y. T. Xanthohumol, a novel anti-HIV-1 agent purified from Hops Humulus lupulus. Antiviral Res. 64, 189-194 (2004). 